УДК 616-006-089.814

DOI: $10.26435 /$ UC.V0I2(35).494

\author{
А.Д. Зубов, А.П. Зятьева
}

ГОО ВПО «Донецкий национальный медицинский университет имени М. Горького», Донецк

\title{
АЛЬТЕРНАТИВНЫЙ ВЗГЛЯД НА АКТИВАЦИЮ НЕОПЛАСТИЧЕСКОГО АНГИОГЕНЕЗА В ОПУХОЛЕВОЙ ТКАНИ
}

На сегодняшний день проблемы выбора адекватной схемы лечения и прогнозирования исхода заболевания считаются первостепенными в клинической практике [4]. Ввиду быстрой прогрессии, агрессивного роста, активного ангиогенеза, интенсивной инвазии и резистентности опухолей головного мозга подходы к традиционной терапии остаются малоэффективными [5]. В качестве молекулярной мишени для антиангиогенной терапии рассматривают VEGFR2, так как данная структура считается основным рецептором проангиогенного сигнала. Однако первые же клинические исследования препаратов, потенциально ингибирующих неопластический ангиогенез, выявили, что не все опухоли отвечали на анти-VEGF-терапию, эффективность антиангиогенных препаратов в клинической практике оказывается существенно ниже [5].

Как известно, для роста опухоли необходима собственная система кровоснабжения: большое количество сосудов обеспечивает постоянное поступление питательных веществ и кислорода, что способствует дальнейшей пролиферации опухолевых клеток. С одной стороны, высокая степень васкуляризации обеспечивает усиленное кровоснабжение и трофику, с другой - создает нишу для периваскулярного роста и распространения, способствуя формированию отдаленных метастазов. Следует отметить, что в отсутствие кровоснабжения опухоль не может превысить 2 мм в диаметре из-за развивающейся гипоксии, приводящей к гибели опухолевых клеток [3]. Именно поэтому подходы, направленные на подавление нерегулируемого ангиогенеза и инволюцию атипичных сосудов, рассматривают как важный инструмент в борьбе с онкологическими заболеваниями. [29, 28, 32].

В норме неопластический ангиогенез активируется в пре- и постнатальный период развития организма, при формировании плаценты и желтого тела, при заживлении ран. Для данных случаев характерны следующие пути формирования сосудов: васкулогенез (дифференциров- ка ангиобластов в эндотелиоциты у эмбриона), ангиогенез (прорастание новых сосудов из уже имеющейся сети сосудов) и инвагинация с разделением сосудистой стенки и образованием дочерних сосудов [7, 22, 30].

Долгое время было принято считать, что активация неопластического ангиогенеза в патологии типична только для опухолевой ткани, однако данное явление характерно для следующих патологических состояний: системные заболевания, возрастная макулярная дегенерация сетчатки, псориаз, бронхиальная астма, сахарный диабет, ожирение [7]. Следует отметить, что для канцерогенеза существуют специфические пути формирования сосудов: сосудистое кооптирование (присвоение опухолью имеющихся сосудов), васкулогенная мимикрия (выстилка просвета сосуда клетками опухоли) и дифференцировка опухолевых клеток в эндотелиоциты [32-33].

В свою очередь, пониженная активность ангиогенеза отмечается в старости и при таких заболеваниях, как болезнь Альцгеймера, атеросклероз периферических сосудов, инсульт и др. $[10,17]$.

С целью благополучной коррекции патологического ангиогенеза необходимо внести некоторую ясность в механизмы формирования сосудов. Неопластический ангиогенез активируется под воздействием следующих веществ:

1) факторы роста - фактор роста эндотелия сосудов (VEGF), эпидермальный фактор роста (EGF), трансформирующие факторы роста (TGF- $\alpha,-\beta)$, фактор роста фибробластов (FGF), тромбоцитарный фактор роста (PDGF), инсулиноподобный фактор роста-1 (IGF-1), плацентарный фактор роста (PlGF);

2) ангиогенин, ангиопоэтин-1;

3) гормоны (лептин, эритропоэтин);

(c) А.Д. Зубов, А.П. Зятьева, 2020

(c) Университетская Клиника, 2020 
4) колониестимулирующие факторы (G-CSF, GM-CSF);

5) активаторы плазминогена;

6) интерлейкин-8;

7) белки базальной мембраны (интегрины, кадгерины и др.);

8) матриксные металлопротеиназы (MMPs).

Ангиогенез ингибируют растворимые рецепторы VEGF (sVEGFR), ангиопоэтин-2, вазостатин, ангиостатин (фрагмент плазминогена), эндостатин, интерферон- $\alpha,-\beta,-\gamma$, интерлейкин-4, $-12,-18$, индуцибельный протеин-10, тромбоспондин, тромбоцитарный фактор-4, ретиноиды, ингибиторы матриксных металлопротеаз (TIMP-1, -2), гормоны (пролактин) [9, 20].

В настоящее время считается, что ключевую роль в регуляции неопластического ангиогенеза играют фактор роста эндотелия(VEGF) сосудов и его тирозинкиназные рецепторы первого и второго типа (VEGF, VEGFR2) $[15,19]$.

Впервые выделил биологические свойства VEGF-A и дал соответствующее название молекуле VEGF Наполеон Феррара в 1989 году [16]. VEGF-A является гликопротеидом, его молекулярная масса приблизительно равна 45 кД. Был идентифицирован ряд изоформ VEGF-A: VEGF$121,-145,-162,-165,-165 b,-183,-189,-206$. Кроме аминокислотного состава, гликопротеиды отличаются по способности проникать через биологические мембраны и связывать гепарин [23]. Введение VEGF приводит к быстрому кратковременному повышению проницаемости сосудов.

Изучено 2 вида тирозинкиназных рецепторов к VEGF-A-VEGFR-1 и VEGF-A-VEGFR-2. Экспрессия и сигнальные пути VEGFR-1 изменяются в процессе онтогенеза, они неодинаковы у эндотелиальных и других видов клеток [7]. Рецептор VEGFR-1 связывает молекулы VEGF-A, -B и PIGF. VEGFR-1, в результате в клетках эндотелия инициируется высвобождение факторов роста, активация матриксных металлопротеиназ (ММР-9). Кроме того, он участвует в регуляции гемопоэза и хемотаксисе моноцитов [18].

Рецептор VEGFR-2 связывает VEGF-A с высокой афинностью, а также имеет сродство к VEGF-C и -D. VEGFR-2 опосредует основные свойства VEGF-A-активацию ангиогенеза и повышение проницаемости эндотелия. При связывании с лигандом происходит димеризация и фосфорилирование рецептора, активируется сигнальный путь повышения выживаемости, хемотаксиса и митоза [21]. Важно отметить, что эффект от активации мембранного рецептора отличен от активации внутриклеточного рецептора, артериальный морфогенез индуцируется лишь по сигнальному пути внутриклеточного
VEGFR-2. В качестве молекулярной мишени для антиангиогенной терапии рассматривают VEGFR2, так как данная структура считается основным рецептором проангиогенного сигнала [27].

Несмотря на многообещающие результаты экспериментальных исследований, эффективность анти-VEGF-препаратов оказывается существенно ниже: не все опухоли реагируют на анитиангиогенную терапию [5].

Допустимо предположить, что данный феномен объясняется активацией других типов роста сосудов, менее чувствительных к действию ингибиторов VEGF, к ним относятся: васкулогенез (из циркулирующих прогениторных клеток), инвагинация, сосудистое кооптирование, васкулогенная мимикрия, дифференцировка опухолевых клеток в эндотелиоциты [19].

Васкулогенная мимикрия - это образование микроваскулярной сети неэндотелиальными клетками, т.е происходящее независимо от ангиогенеза. Она включает в себя формирование высокоструктурированных васкулярных каналов, ограниченных базальной мембраной из опухолевых клеток, без участия эндотелиальных клеток и фибробластов. Опухолевые клетки в результате частичной трансдифференцировки в эндотелий-подобные клетки способны имитировать поведение эндотелиальных клеток и инициировать формирование васкулярных каналов в опухоли (однако в некоторых источниках присутствует информация о том, что васкулярные каналы могут быть сформированы стромальными клетками, макрофагами или тучными клетками) [25]. На данный момент васкулогенная мимикрия обнаружена практически во всех опухолях, и её появление ассоциируется с плохим прогнозом [2].

Кроме того, антиангиогенная терапия вызывает гипоксию, приводящую к стабилизации HIFla [24], метаболическому переходу к гликолизу, активации PI3K-и Wnt-сигнальных путей, уменьшению числа митохондрий [26]. Также обнаружена положительная регуляция и других ангиогенезозависимых генов, включая VEGF-A, который активирует различные сигнальные пути, в то время как современная антиангиогенная терапия направлена на подавление активности VEGFp-2. Так, активация VEGF-A и других сигнальных путей, таких как PI3K/Akt, в условиях гипоксии приводит к увеличению внутриклеточного уровня глюкозы [28], стимуляции гликолиза и накоплению молочной кислоты, вследствие чего запускается инвазия и метастазирование. В то же время происходит снижение чувствительности малигнизированных клеток к гипоксии, что вызывает повышение резистентности к антиангиогенной терапии [35]. 
Показано, что компенсаторные механизмы сосудистой поддержки в ответ на антиангиогенную терапию могут быть связаны с эндотелиальными клетками опухолевого происхождения, которые образуются в результате трансдифференцировки [34]. Этот феномен хорошо известен как мозаичность сосудов. Важными факторами такой дифференциации являются условия гипоксии и регуляторный белок HIFla. Следует отметить, что данный процесс не зависит от VEGF, поэтому эндотелиальные клетки опухолевого происхождения устойчивы к ингибиторам VEGF и могут быть одним из факторов резистентности опухолей, т.е. в данном случае применение антиангиогенной терапии неэффективно [5].

Допустимо предположить, что активация неопластического ангиогенеза в опухолевой ткани является следствием активации рецептора CD31 (РЕСАМ-1), в результате взаимодействия с данным рецептором активируются реакции синтеза VEGF и других стимуляторов ангиогенеза.

Ген РЕСАМ-1 расположен на участке 17q23.3, содержит 16 экзонов, 1-8 экзоны кодируют экстрацеллюлярный домен, который ответствен за связывание PECAM1 с другими молекулами и миграцию клеток [1]. Полиморфизм 373 C>G приводит к замене аминокислоты Leu на Val в положении 125. Имеются данные о том, что PECAM-1 (CD31), наряду с другими представителями молекул клеточной адгезии, характерен для метастатической прогрессии при меланоме, глиоме, опухоли молочной железы, яичников, простаты и др. [33].

Долгое время было принято считать, что CD31 регулирует и адгезию эндотелия, и миграцию, опосредованную межклеточными взаимодействиями [30]. Эти клеточные процессы происходят при тесном взаимодействии клеток друг с другом и микроокружением. В нормальной ткани экспрессия молекул клеточной адгезии жестко регулируется [1]. Однако дисбаланс молекул клеточной адгезии нарушает нормальные межклеточные взаимодействия и содействует формированию опухоли и метастазированию. Было выяснено, что CD31 отвечает за адгезию опухолевых клеток. На данный момент CD31 является прогностическим ангиоиммуномаркером, по его титру определяют уровень васкуляризации опухоли, повышение титра коррелирует с плохим прогнозом $[1,6]$.

Известно, что изменение структуры всегда приводит к изменению функции. Таким обра- зом, в результате активации рецептора CD31 изменяется конформация белка и возникает перестройка эндотелиального гликокаликса. Данные изменения отражаются в структуре цитоскелета, что позволяет объяснить причину атипизма интратуморальных сосудов.

\section{З А К ЛЮ ЧЕН ИЕ}

Результаты научных исследований последних лет позволяют открыть новую страницу в оценке патофизиологического значения неоангиогенеза и учета васкулогенного компонента в микроциркуляции крови в опухоли. Обнаружена положительная регуляция ряда ангиогенезозависимых генов, установлено, что ингибирование отдельного компонента (VEGF-нейтрализующими антителами) или даже локального участка сигнального пути (VEGFR2-низкомолекулярными ингибиторами тирозинкиназы) не может контролировать работу всей системы в целом. Данное явление обусловлено тем, что экспрессия VEGF характерна для нормального роста сосудов, в то же время существуют пути формирования сосудов, которые характерны для канцерогенеза, рост данных сосудов осуществляется независимо от VEGF. Это является основной причиной неэффективности антиангиогенной терапии. Также резистентность к антиангиогенной терапии связана с повышением уровня экспрессии факторов роста и с активацией альтернативных проангиогенных путей [12], привлечением предшественников эндотелиальных клеток из костного мозга [13], увеличением вклада периваскулярного инвазивного роста в прогрессию опухоли и переключением на анаэробный метаболизм глюкозы [26, 31].

Следовательно, при осуществлении лечения опухолей необходимо учитывать наличие специфических путей формирования сосудов (характерных для канцерогенеза), наличие альтернативных путей стимуляции неоангиогенеза в опухоли. В настоящее время CD31 (PECAM-1) является прогностическим ангиоиммуномаркером, высокий титр данного гликопротеида коррелирует с неблагоприятным прогнозом у онкобольных, также PECAM-1 играет определённую роль в формировании патологических типов сосудов (сосудистое кооптирование, васкулогенная мимикрия, дифференцировка опухолевых клеток в эндотелиоциты. Таким образом, актуальным направлением для дальнейших исследований является возможность ингибирования рецептора CD31 в опухолевой ткани. 


\section{А.Д. Зубов, А.П. Зятьева}

ГОО ВПО «Донецкий национальный медицинский университет имени М. Горького», Донецк

\section{АЛЬТЕРНАТИВНЫЙ ВЗГЛЯД НА АКТИВАЦИЮ НЕОПЛАСТИЧЕСКОГО АНГИОГЕНЕЗА В ОПУХОЛЕВОЙ ТКАНИ}

Проведен анализ современного состояния вопроса роли неопластического ангиогенеза в росте, инвазии, метастазировании опухоли и путях его фармакологической коррекции.

Неопластический ангиогенез - это процесс формирования новых атипичных сосудов в опухолевой ткани, который играет ключевую роль в инвазии и метастазировании опухолей, данное утверждение является общепризнанным. Современные антиангогенные препараты направлены на подавление активности рецептора фактора роста эндотелия второго типа (VEGFR-2), сегодня он считается основным рецептором трансдукции проангиогенного сигнала. Однако действие этих препаратов в лечении злокачественных опухолей малоэффективно. Данный факт обусловлен тем, что фактор роста эндотелия влияет на рост нормальных сосудов, в то же время существуют иные пути формирования сосудов при канцерогенезе, не зависящие от VEGF. Следовательно, при осуществлении лечения опухолей необходимо учитывать наличие специфических путей формирования сосудов и альтернативных путей стимуляции неоангиогенеза в опухоли. Допустимо предположить, что CD31 играет ключевую роль в формировании атипичных сосудов, следовательно, активным направлением для дальнейших исследований является изучение возможности ингибирования рецептора CD31 в опухолевой ткани.

Ключевые слова: злокачественное новообразование, неопластический ангиогенез, фактор роста эндотелия сосудов, CD31.

\section{A.D. Zubov, A.P. Zyatieva}

SEI HPE «M. Gorky Donetsk National Medical University», Donetsk

\section{ALTERNATIVE APPROACH TO ACTIVATION OF NEOPLASTIC ANGIOGENESIS IN TUMOUR TISSUE}

We have analyzed the contemporary state of the question about the role of neoplastic angiogenesis in growth, invasion, metastatic spreading of tumours and ways of pharmacological correction.

Neoplastic angiogenesis is the process of formation of new atypical vessels in tumour tissue. It is generally recognized that it causes invasion and metastatic spreading of tumours. Modern antiangiogenesis drugs target in suppressing activity of receptor for vascular endothelial growth factor of the second type (VEGFR-2), nowadays it is considered to be the main receptor of proangiogenic signal transduction. Nevertheless, the use of these drugs for treatment of malignant tumours is not effective. It can be explained by the fact that vascular endothelial growth factor influences the growth of normal vessels, there are also different ways of vessel formation while cancerogenesis, regardless of VEGF. Consequently, while treating tumours it is necessary to consider specific ways of vessel formation and alternative ways of neoangiogenesis stimulation within tumour. It can be assumed that CD31 is the basic reason of atypical vessels formation, therefore, the progressive direction for further research is the study of possibility of receptor CD31 inhibition in tumour tissue.

Key words: malignant tumours, neoplastic angiogenesis, vascular endothelial growth factor, CD31.

\section{ЛИТЕРАТУРА}

1. Ахмадишина Л.З., Корытина Г.Ф., Кочетова О.В., Шаймухаметова М.М., Измайлова С.М., Измайлов А.А., Викторова Т.В., Кабиров И.Р. Поиск ассоциации полиморфных локусов VEGF, vcam1, ресаm1, ICAM1 с риском развития рака мочевого пузыря. Медицинский вестник Башкортостана. 2015; 10 (3 (57)): 209-212.

2. Вартанян А.А. Альтернативное кровоснабжение в костном мозге при онкогематологических заболеваниях. Клиническая онкогематология. Фундаментальные исследования и клиническая практика. 2014; 7(4): 491-500.

3. Вартанян А.А. Основные закономерности ангиогенеза при онкогематологических заболеваниях. Клиническая онкогематология. Фундаментальные исследования и клиническая практика. 2013; 6 (4): 343-353.

4. Гапеенко Е.В., Державец Л.А. Опухолевые маркеры, факторы роста, регуляторы ангиогенеза в диагностике и мониторинге рака молочной железы. Онкологический журнал. 2013; 3(27): 86-95.

\section{REFERENCES}

1. Akhmadishina L.Z., Korytina G.F., Kochetova O.V., Shaymukhametova M.M., Izmaylova S.M., Izmaylov A.A., Viktorova T.V., Kabirov I.R. Poisk associaciy polimorfnyh lokusov VEGF, vcam1, pecam1, ICAM1 s riskom razvitiya raka mochevogo puzyrya. Medicinskiy vestnik Bashkortostana. 2015; 3 (57): 209-212 (in Russian).

2. Vartanyan A.A. Alternativnoye krovosnabzhenie v kostnom mozge pri onkogematologicheskih zabolevaniyah. Klinicheskaya onkogematologiya. Fundamentalnye issledovaniya i klinicheskaya praktika. 2014; 7 (4): 491-500 (in Russian).

3. Vartanyan A.A. Osnovnye zakonomernosti angiogeneza pri onkogematologicheskih zabolevaniyah. Klinicheskaya onkogematologiya. Fundamentalniye issledovaniya i klinicheskaya praktika. 2013; 6 (4): 343-353 (in Russian).

4. Gapeenko E.V., Derzhavets L.A. Opukholeviye markery, faktory rosta, regulyatory angiogeneza $v$ diagnostike $i$ monitoringe raka molochnoj zhelezy. Onkologicheskiy zhurnal. 2013; 3(27): 86-95 (in Russian). 
5. Корчагина А.А., Шеин С.А., Гурина О.И., Чехонин В.П. Роль рецепторов VEGFR в неопластическом ангиогенезе и перспективы терапии опухолей мозга. Вестник Российской академии медицинских наук. 2013; 68 (11), 104-114.

6. Рудимов Е., Буравкова Л. Гравичувствительность эндотелия: роль цитоскелета и молекул адгезии. Физиология человека. 2016; 42(6): 116-123. doi:10.7868/ s0131164616060175

7. Светозарский Н.Л., Артифексова А.А., Светозарский С.Н. Фактор роста эндотелия сосудов: биологические свойства и практическое значение (обзор литературы). Journal of Siberian Medical Sciences. 2015; (5): 24.

8. Хоченкова Ю. А., Чкадуа Г.З., Самойленко И.В., Маливанова Т.Ф., Михайлова И.Н., Демидов Л.В., Степанова Е.В. Значимость однонуклеотидных полиморфизмов $-2578 \mathrm{c}>\mathrm{a}$ и +936c>t гена VEGF для оценки эффективности противоопухолевой иммунотерапии метастатической меланомы кожи. Медицинская иммунология. 2013; 15 (6): 563-570.

9. Чехонин В. П., Шеин С.А., Корчагина, А.А., Гурина О.И. Роль VEGF в развитии неопластического ангиогенеза. Вестник Российской академии медицинских наук. 2012; 67 (2): 23-34.

10. Carmeliet P. Angiogenesis in health and disease. Nature Medicine. 2003; 9(6): 653-660.

11. Carmeliet P., Jain R. Molecular mechanisms and clinical applications of angiogenesis. Nature. 2011; 473(7347): 298-307.

12. di Tomaso E., London N., Fuja D., Logie J., Tyrrell J., Kamoun W., Munn L., Jain R. PDGF-C Induces Maturation of Blood Vessels in a Model of Glioblastoma and Attenuates the Response to Anti-VEGF Treatment. PLoS ONE. 2009; 4(4): 5123.

13. Du R., Lu K., Petritsch C., Liu P., Ganss R., Passegué E., Song H., VandenBerg S., Johnson R., Werb Z., Bergers, G. HIF $1 \alpha$ Induces the Recruitment of Bone Marrow-Derived Vascular Modulatory Cells to Regulate Tumor Angiogenesis and Invasion. Cancer Cell. 2008; 13(3): 206-220.

14. Fan F., Samuel S., Gaur P., Lu J., Dallas N., Xia L., Bose D., Ramachandran V., Ellis, L. Chronic exposure of colorectal cancer cells to bevacizumab promotes compensatory pathways that mediate tumour cell migration. British Journal of Cancer: 2011; 104(8): 1270-1277.

15. Ferrara N. Davis-Smyth T. The Biology of Vascular Endothelial Growth Factor. Endocrine Reviews. 1997; 18(1): 4-25.

16. Ferrara N., Henzel W. Pituitary follicular cells secrete a novel heparin-binding growth factor specific for vascular endothelial cells. Biochemical and Biophysical Research Communications. 1989; 161(2): 851-858.

17. Ferrara N., Kerbel R. Angiogenesis as a therapeutic target. Nature, 2005; 438(7070): 967-974.

18. Ferrara N., Gerber H., LeCouter, J. The biology of VEGF and its receptors. Nature Medicine. 2003; 9(6): 669-676.

19. Ferrara N. Molecular and biological properties of vascular endothelial growth factor. Journal of Molecular Medicine. 1999; 77(7): 527-543.

20. Ferrara N. Vascular Endothelial Growth Factor: Basic Science and Clinical progress. Endocr. Rev. 2004; 25: 581611.

21. Ferrara N. VEGF-A: a critical regulator of blood vessel growth. European Cytokine Network. 2009; 20(4): 158163.

22. Folkman J. Angiogenesis: an organizing principle for drug discovery? Nature Reviews Drug Discovery. 2007; 6(4): 273-286.

23. Grünewald F., Prota A., Giese A., Ballmer-Hofer K. Structure-function analysis of VEGF receptor activation and the role of coreceptors in angiogenic signaling. Biochimica et Biophysica Acta (BBA) - Proteins and Proteomics. 2010; 1804(3): 567-580.

24. Hendriksen E., Span P., Schuuring J., Peters J., Sweep F., van der Kogel A., Bussink, J. Angiogenesis, hypoxia and VEGF expression during tumour growth in a human xenograft tumour model. Microvascular Research. 2009; 77(2):
5. Korchagina A.A., Shein S.A., Gurina O.I., Chekhonin V.P. Rol' retseptorov VEGFR v neoplasticheskom angiogeneze i perspektivy terapii opukholey mozga. Vestnik Rossiyskoy akademii medicinskikh nauk. 2013; 68 (11): 104-114 (in Russian).

6. Rudimov E., Buravkova L. Gravichuvstvitelnost endoteliya: rol' tsitoskeleta i molekul adgezii. Fiziologiya cheloveka. 2016; 42 (6):116-123 (in Russian). doi:10.7868/ s0131164616060175

7. Svetozarskiy N.L., Artifeksova A.A., Svetozarskiy S.N. Faktor rosta endoteliya sosudov: biologicheskiye svoystva i prakticheskoe znachenie (obzor literatury). Journal of Siberian Medical Sciences. 2015; (5): 24 (in Russian).

8. Hochenkova YU. A., Chkadua G.Z., Samoylenko I.V., Malivanova T.F., Mikhaylova I.N., Demidov L.V., Stepanova E.V. Znachimost odnonukleotidnykh polimorfizmov $-2578 c>a$ i +936c >t gena VEGF dlya otsenki effektivnosti protivoopukholevoy immunoterapii metastaticheskoy melanomy kozhi. Meditsinskaya immunologiya. 2013; 15 (6): 563-570 (in Russian).

9. Chekhonin V. P., Shein S. A., Korchagina, A. A., Gurina O. I. Rol' VEGF v razvitii neoplasticheskogo angiogeneza. Vestnik Rossiyskoy akademii meditsinskikh nauk. 2012; 67 (2): 23-34 (in Russian).

10. Carmeliet P. Angiogenesis in health and disease. Nature Medicine. 2003; 9(6): 653-660.

11. Carmeliet P., Jain R. Molecular mechanisms and clinical applications of angiogenesis. Nature. 2011; 473(7347): 298-307.

12. di Tomaso E., London N., Fuja D., Logie J., Tyrrell J., Kamoun W., Munn L., Jain R. PDGF-C Induces Maturation of Blood Vessels in a Model of Glioblastoma and Attenuates the Response to Anti-VEGF Treatment. PLoS ONE. 2009; 4(4): 5123.

13. Du R., Lu K., Petritsch C., Liu P., Ganss R., Passegué E., Song H., VandenBerg S., Johnson R., Werb Z., Bergers, G. HIF $1 \alpha$ Induces the Recruitment of Bone Marrow-Derived Vascular Modulatory Cells to Regulate Tumor Angiogenesis and Invasion. Cancer Cell. 2008; 13(3): 206-220.

14. Fan F., Samuel S., Gaur P., Lu J., Dallas N., Xia L., Bose D., Ramachandran V., Ellis, L. Chronic exposure of colorectal cancer cells to bevacizumab promotes compensatory pathways that mediate tumour cell migration. British Journal of Cancer: 2011; 104(8): 1270-1277.

15. Ferrara N. Davis-Smyth T. The Biology of Vascular Endothelial Growth Factor. Endocrine Reviews. 1997; 18(1): 4-25.

16. Ferrara N., Henzel W. Pituitary follicular cells secrete a novel heparin-binding growth factor specific for vascular endothelial cells. Biochemical and Biophysical Research Communications. 1989; 161(2): 851-858.

17. Ferrara N., Kerbel R. Angiogenesis as a therapeutic target. Nature, 2005; 438(7070): 967-974.

18. Ferrara N., Gerber H., LeCouter, J. The biology of VEGF and its receptors. Nature Medicine. 2003; 9(6): 669-676.

19. Ferrara N. Molecular and biological properties of vascular endothelial growth factor. Journal of Molecular Medicine. 1999; 77(7): 527-543.

20. Ferrara N. Vascular Endothelial Growth Factor: Basic Science and Clinical progress. Endocr. Rev. 2004; 25: 581611.

21. Ferrara N. VEGF-A: a critical regulator of blood vessel growth. European Cytokine Network. 2009; 20(4): 158163.

22. Folkman J. Angiogenesis: an organizing principle for drug discovery? Nature Reviews Drug Discovery. 2007; 6(4): 273-286.

23. Grünewald F., Prota A., Giese A., Ballmer-Hofer K. Structure-function analysis of VEGF receptor activation and the role of coreceptors in angiogenic signaling. Biochimica et Biophysica Acta (BBA) - Proteins and Proteomics. 2010; 1804(3): 567-580.

24. Hendriksen E., Span P., Schuuring J., Peters J., Sweep F., van der Kogel A., Bussink, J. Angiogenesis, hypoxia and VEGF expression during tumour growth in a human xenograft tumour model. Microvascular Research. 2009; 77(2): 
96-103.

25. Hendrix M., Seftor E., Hess A., Seftor R. Molecular plasticity of human melanoma cells. Oncogene. 2003; 22(20): 3070-3075.

26. Keunen O., Johansson M., Oudin A., Sanzey M., Rahim S., Fack F., Thorsen F., Taxt T., Bartos M., Jirik R., Miletic H., Wang J., Stieber D., Stuhr L., Moen I., Rygh C., Bjerkvig R., Niclou S. Anti-VEGF treatment reduces blood supply and increases tumor cell invasion in glioblastoma. Proceedings of the National Academy of Sciences. 2011; 108(9): 37493754 .

27. Lanahan A., Hermans K., Claes F., Kerley-Hamilton J., Zhuang Z., Giordano F., Carmeliet P., Simons M. VEGF Receptor 2 Endocytic Trafficking Regulates Arterial Morphogenesis. Developmental Cell. 2010; 18(5): 713-724.

28. Miletic H., Niclou S., Johansson M., Bjerkvig R. AntiVEGF therapies for malignant glioma: treatment effects and escape mechanisms. Expert Opinion on Therapeutic Targets. 2009; 13(4): 455-468.

29. Norden A., Drappatz J., Wen P. Antiangiogenic therapies for high-grade glioma. Nature Reviews Neurology. 2009; 5(11): 610-620.

30. Park S., DiMaio T., Scheef E., Sorenson C., Sheibani N. PECAM-1 regulates proangiogenic properties of endothelial cells through modulation of cell-cell and cell-matrix interactions. American Journal of Physiology-Cell Physiology. 2010; 299(6): 1468-1484.

31. Ricci-Vitiani L., Pallini R., Biffoni M., Todaro M., Invernici G., Cenci T., Maira G., Parati E., Stassi G., Larocca L., De Maria R. Tumour vascularization via endothelial differentiation of glioblastoma stem-like cells. Nature. 2010; 468(7325): 824-828.

32. Tong R., Boucher Y., Kozin S., Winkler F., Hicklin, D., Jain R. Vascular Normalization by Vascular Endothelial Growth Factor Receptor 2 Blockade Induces a Pressure Gradient Across the Vasculature and Improves Drug Penetration in Tumors. Cancer Research. 2004; 64(11): 3731-3736.

33. Wai Wong C., Dye D., Coombe D. The Role of Immunoglobulin Superfamily Cell Adhesion Molecules in Cancer Metastasis. International Journal of Cell Biology. 2012; 1 : 1-9.

34. Wang R., Chadalavada K., Wilshire J., Kowalik U., Hovinga K., Geber A., Fligelman B., Leversha M., Brennan C., Tabar V. Glioblastoma stem-like cells give rise to tumour endothelium. Nature. 2010; 468(7325): 829-833.

35. Yu J. Effect of p53 Status on Tumor Response to Antiangiogenic Therapy. Science. 2002; 295(5559): 1526-1528.
96-103.

25. Hendrix M., Seftor E., Hess A., Seftor R. Molecular plasticity of human melanoma cells. Oncogene. 2003; 22(20): 3070-3075.

26. Keunen O., Johansson M., Oudin A., Sanzey M., Rahim S., Fack F., Thorsen F., Taxt T., Bartos M., Jirik R., Miletic H., Wang J., Stieber D., Stuhr L., Moen I., Rygh C., Bjerkvig R., Niclou S. Anti-VEGF treatment reduces blood supply and increases tumor cell invasion in glioblastoma. Proceedings of the National Academy of Sciences. 2011; 108(9): 37493754.

27. Lanahan A., Hermans K., Claes F., Kerley-Hamilton J., Zhuang Z., Giordano F., Carmeliet P., Simons M. VEGF Receptor 2 Endocytic Trafficking Regulates Arterial Morphogenesis. Developmental Cell. 2010; 18(5): 713-724.

28. Miletic H., Niclou S., Johansson M., Bjerkvig R. AntiVEGF therapies for malignant glioma: treatment effects and escape mechanisms. Expert Opinion on Therapeutic Targets. 2009; 13(4): 455-468.

29. Norden A., Drappatz J., Wen P. Antiangiogenic therapies for high-grade glioma. Nature Reviews Neurology. 2009; 5(11): 610-620.

30. Park S., DiMaio T., Scheef E., Sorenson C., Sheibani N. PECAM-1 regulates proangiogenic properties of endothelial cells through modulation of cell-cell and cell-matrix interactions. American Journal of Physiology-Cell Physiology. 2010; 299(6): 1468-1484.

31. Ricci-Vitiani L., Pallini R., Biffoni M., Todaro M., Invernici G., Cenci T., Maira G., Parati E., Stassi G., Larocca L. De Maria R. Tumour vascularization via endothelial differentiation of glioblastoma stem-like cells. Nature. 2010; 468(7325): 824-828

32. Tong R., Boucher Y., Kozin S., Winkler F., Hicklin, D., Jain R. Vascular Normalization by Vascular Endothelial Growth Factor Receptor 2 Blockade Induces a Pressure Gradient Across the Vasculature and Improves Drug Penetration in Tumors. Cancer Research. 2004; 64(11): 3731-3736.

33. Wai Wong C., Dye D., Coombe D. The Role of Immunoglobulin Superfamily Cell Adhesion Molecules in Cancer Metastasis. International Journal of Cell Biology. 2012; 1: 1-9.

34. Wang R., Chadalavada K., Wilshire J., Kowalik U., Hovinga K., Geber A., Fligelman B., Leversha M., Brennan C., Tabar V. Glioblastoma stem-like cells give rise to tumour endothelium. Nature. 2010; 468(7325): 829-833.

35. Yu J. Effect of p53 Status on Tumor Response to Antiangiogenic Therapy. Science. 2002; 295(5559): 1526-1528. 